\title{
Interval Aerobic Exercise versus Cupping Therapy on Essential Hypertension in Women
}

\author{
AZZA A. ABD EL-HADY, Ph.D.*; SHEREEN H. EL-SAYED, Ph.D.**; \\ WAEL ABO SHOKKA, M.D.* and LAMIA M. FAHMY, M.Sc.* \\ The Department of Cardiovascular, Respiratory Disorders \& Geriatrics, Faculty of Physical Therapy, \\ Cairo University* and the Department of Cardiology, Faculty of Medicine, Heart Institute**, Giza, Egypt
}

\begin{abstract}
Background: Exercise and cupping therapy has been suggested to be available treatment for hypertension. This study compares the effect of interval aerobic exercise versus cupping on essential hypertensive women.
\end{abstract}

Aim of the Study: To determine the effect of interval aerobic exercise versus cupping therapy on Essential Hypertensive women.

Subject and Methods: Thirty women had essential hypertension stage: 1 (140: $160 \mathrm{mmHg}$ systole- $90-100 \mathrm{mmHg}$ diastole) were randomly assigned into two groups equal in number. Group (A) fifteen women received moderate intensity (aerobic interval) exercise (4 to 7) of modified 0-10 Borg scale, exercise session 15:20min, three times per week for a month. Group (B) fifteen women received cupping therapy session on six points in the neck and back 20min, one session at the beginning of a study month.

Results: Significant reduction of systolic blood pressure at post-treatment in comparison to pre-treatment $(p$-value $=$ $0.0001 *)$. There was improvement of systolic blood pressure in group: A percent of change (improvement) was $13.79 \%$. There was improvement of systolic blood pressure in Group B percent of change (improvement) was $11.5 \%$, multiple pair wise comparison tests (post hoc tests) revealed that there was no significant difference of the mean values of the "post" test between both groups with $(p=0.096)$. In spite of that there was no statistical significant difference between Group A and Group B, was clinical difference and high percent of improvement in favor to Group A. There was improvement of diastolic blood pressure in Group A and percent of change (improvement) was $11.96 \%$. Multiple pair wise comparison tests (post hoc tests) revealed that there was significant reduction of diastolic blood pressure at post-treatment in compare to pretreatment $(p$-value $=0.0001 *)$ this mean there was improvement of diastolic blood pressure in Group B and percent of change (improvement) was $13.19 \%$. In spite of there was no statistical significant difference between Group A and Group B, there

Correspondence to: Dr. Azza A. Abd El-Hady, The Department of Cardiovascular, Respiratory Disorders \& Geriatrics, Faculty of Physical Therapy, Cairo University was clinical difference and high percent of improvement in favor to Group B.

Conclusion: It was concluded that participation in aerobic interval exercise or cupping therapy have positive effect on blood pressure in stage one essential hypertensive women and can be used as alternative treatment modalities.

Key Words: Essential hypertension - Interval aerobic exercise - Cupping therapy.

\section{Introduction}

CARDIOVASCULAR diseases deaths about $30.3 \%$ of all deaths worldwide [1]. One of the important causes of cardiovascular diseases is hypertension. Hypertension is classified as either primary (essential) hypertension or secondary hypertension; about $90-95 \%$ of cases are categorized as "primary hypertension" which means high blood pressure with no obvious underlying medical cause. The remaining 5-10\% of cases (secondary hypertension) is caused by other conditions that affect the kidneys, arteries, heart or endocrine system. Hypertension is a major risk factor for stroke, myocardial infarction (heart attacks), heart failure, aneurysms of the arteries (e.g. aortic aneurysm), peripheral arterial disease and is a cause of chronic kidney disease [2]

Interval exercise training has now been examined in a wide variety of individuals, ranging from elite athletes to patients with severe cardiovascular disease. The advantages of interval exercise training programmes in comparison with constant intensity exercise programmes are that they appear to deliver superior improvements in several cardiovascular risk factors, fitness and performance. Depending on the design, some interval exercise programmes result in a range of benefits, even though the time 
commitment may be dramatically less than more traditional continuous intensity programmes [3].

Cupping is the practice of applying a partial vacuum by means of heat or suction in one or several bell-shaped vessels (suction cups) to specific and different parts of the skin. The procedure is one of the oldest and most effective methods of releasing toxins from the body tissues and organs. Cupping is a safe, non-invasive and inexpensive technique [4]

\section{Subjects and Methods}

Thirty women patients represented the sample of this study and all women suffered from stage I essential hypertension. This study was conducted in outpatient clinic in (Al-Safwa Clinic and Ain Shams Public Hospital in Ain Shams Region) from January 2014 to December 2016 to compare cupping therapy versus interval aerobic exercises on essential hypertensive women.

\section{The inclusion criteria:}

Women age (30: 40) years old, Able to perform the therapeutic modality, Have essential hypertension stage I (140-159 mmHg systole) $(90-99 \mathrm{mmHg}$ diastole), Women who did not receive cupping to hypertension before or at least six months prior to the study.

\section{Exclusion criteria:}

Women suffering from serious heart troubles or diseases that render the individual prone to bleeding, pregnant women, women taking contraceptive pills, women with bone fractures or muscle spasms, hypertensive women over 40 , renal disease women.

Subjects were randomly assigned to two groups equal in number:

Group (A): Patients were subjected to aerobic interval training three times per week plus their medication for one month.

Group (B): Patient was subjected to cupping therapy one session at the beginning of the study month plus their medication.

\section{Evaluation procedures:}

A- Measuring blood pressure with Mercury Sphygmomanometer and stethoscope at the beginning of the study and re-evaluated after four weeks.

B- Measuring exercise intensity with: modified (0-10) Borg scale: The Borg Rating of Perceived Exertion (RPE) is a way of measuring physical activity intensity level. The program exercise intensity (4:7) mild to moderate intensity.

Treatment procedures: Group A: (Aerobic interval training program).

All patients in this group were asked to assume sitting position on a stationary bicycle orgometer to do exercise training. The physical therapist explained the aerobic interval exercise training protocol to the patients and determines intensity according to modified (0-10) Borg scale from (4:7) low to moderate intensity, the session time was 15:20min three times per week for one month. Group B: (Cupping therapy program) all patients in this group were asked to assume prone position to receive bloodletting technique on six point in the neck and the back patients take one session (20min) in the beginning of the study month.

\section{Results}

Comparing the general characteristics of the subjects of both groups revealed that there was no significance difference between both groups in the mean age, weight, height, and BMI $(p>0.05)$ (Table 1).

\section{General characteristics:}

The current study was conducted on 30 participants. They were assigned into two equal groups. Group (A) consisted of 15 participants with mean age, body mass, height, and BMI values of $36.33 \pm$ 3.61 years, $101.08 \pm 17.56 \mathrm{~kg}, 157.8 \pm 7.56 \mathrm{~cm}$, and $40.98 \pm 8.95 \mathrm{Kg} / \mathrm{m}^{2}$ respectively. Group (B) consisted of 15 participants with mean age, body mass, height, and BMI values of $35.73 \pm 3.65$ years, $96.6 \pm$ $13.42 \mathrm{~kg}, 155.96 \pm 6.54 \mathrm{~cm}$, and $39.83 \pm 5.92 \mathrm{Kg} / \mathrm{m}^{2}$ respectively. As indicated by the independent $t$ test, there were no significant differences $(p>0.05)$ in the mean values of age, body mass, and height between both tested groups (Table 1).

\section{1- 2 X 2 mixed design MANOVA:}

A- Overall effect: Statistical analysis using 2 $X 2$ mixed design MANOVA indicated that there were no significant effects of the tested group (the first independent variable) on the all tested dependent variables; systolic and diastolic blood pressure $(\mathrm{F}=1.081, p=0.353)$. However, there were significant effects of the measuring periods (the second independent variable) on the tested dependent variables $(\mathrm{F}=166.937, p=0.0001 *)$. However, the interaction between the two independent variables was not significant, which indicates that the effect of the tested group (first independent variable) on the dependant variables was not influenced by the 
measuring periods (second independent variable) $(\mathrm{F}=1.978, p=0.158)$ (Table 2).

\section{B- Multiple pair wise comparison tests: Systolic blood pressure:}

1- Within groups: As presented in (Table 3) and illustrated in Fig. (1), within group's comparison the mean \pm SD values of systolic blood pressure in the "pre" and "post" tests were $149.73 \pm 7.75$ and 129.06 \pm 9.88 respectively in the Group (A). Multiple pair wise comparison tests (post hoc tests) revealed that there was significant reduction of systolic blood pressure at post-treatment in compare to pre-treatment $(p$-value $=0.0001 *)$ and this mean there was improvement of systolic blood pressure in Group A and percent of change (improvement) was $13.79 \%$. While, the mean \pm SD values of systolic blood pressure in the "pre" and "post" tests were $152.4 \pm 8.24$ and $134.86 \pm 8.5$ respectively the Group (B). Multiple pairwise comparison tests (post hoc tests) revealed that there was significant reduction of systolic blood pressure at post treatment in compare to pre-treatment ( $p$-value $=$ $0.0001 *)$ and this mean there was improvement of systolic blood pressure in Group B and percent of change (improvement) was $11.5 \%$.

2- Between groups: Considering the effect of the tested group (first independent variable) on systolic blood pressure, multiple pair wise comparison tests (post hoc tests) revealed that the mean values of the "pre" test between both groups showed no significant differences with $(p=0.369)$. As well as, multiple pair wise comparison tests (post hoc tests) revealed that there was no significant difference of the mean values of the "post" test between both groups with $(p=0.096)$. In spite of there was no statistical significant difference between Group

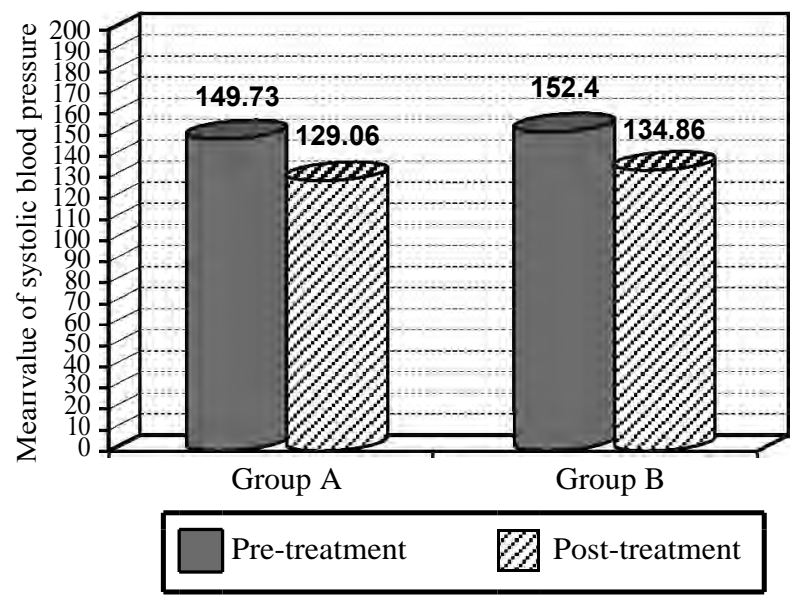

Fig. (1): Mean values of systolic blood pressure pre and posttests in both groups.
A and Group B, there was clinical difference and high percent of improvement in favor to Group A.

\section{Diastolic blood pressure:}

1- Within groups: As presented in (Table 4) and illustrated in Fig. (2), within group's comparison the mean \pm SD values of diastolic blood pressure in the "pre" and "post" tests were $94.2 \pm$ 4.10 and $82.93 \pm 4.57$ respectively in the Group (A). Multiple pairwise comparison tests (post hoc tests) revealed that there was significant reduction of diastolic blood pressure at post-treatment in compare to pre-treatment $\left(p\right.$-value $\left.=0.0001^{*}\right)$ and this mean there was improvement of diastolic blood pressure in Group A and percent of change (improvement) was $11.96 \%$. While, the mean \pm SD values of diastolic blood pressure in the "pre" and "post" tests were $96 \pm 5.35$ and $83.33 \pm 6.48$ respectively the Group (B). Multiple pairwise comparison tests (post hoc tests) revealed that there was significant reduction of diastolic blood pressure at post-treatment in compare to pre-treatment $(p-$ value $\left.=0.0001^{*}\right)$ and this mean there was improvement of diastolic blood pressure in Group B and percent of change (improvement) was $13.19 \%$.

2-Between groups: Considering the effect of the tested group (first independent variable) on diastolic blood pressure, multiple pair wise comparison tests (post hoc tests) revealed that the mean values of the "pre" test between both groups showed no significant differences with $(p=0.311)$. As well as, multiple pair wise comparison tests (post hoc tests) revealed that there was no significant difference of the mean values of the "post" test between both groups with $(p=0.847)$. In spite of there was no statistical significant difference between Group $A$ and Group B, there was clinical difference and high percent of improvement in favor to Group B.

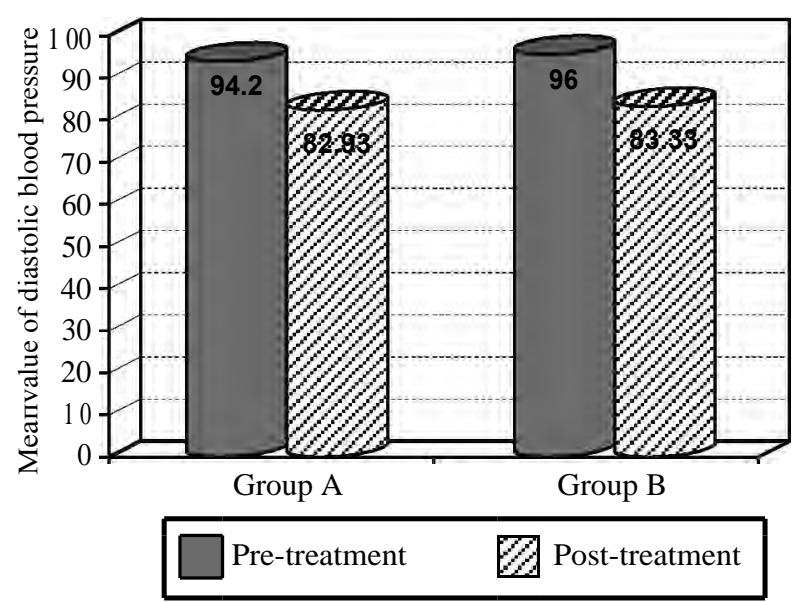

Fig. (2): Mean values of diastolic blood pressure pre and post tests in both groups. 
Table (1): Physical characteristics of participants in both Groups (A \& B).

\begin{tabular}{|c|c|c|c|c|c|}
\hline \multirow{2}{*}{ Items } & \multirow{2}{*}{$\begin{array}{c}\text { Group A } \\
\text { Mean } \pm \text { SD }\end{array}$} & \multirow{2}{*}{$\begin{array}{c}\text { Group B } \\
\text { Mean } \pm \text { SD }\end{array}$} & \multicolumn{2}{|c|}{ Comparison } & \multirow{2}{*}{$S$} \\
\hline & & & $t$-value & $p$-value & \\
\hline Age (years) & $36.33 \pm 3.61$ & $35.73 \pm 3.65$ & 0.452 & 0.655 & NS \\
\hline Body mass $(\mathrm{Kg})$ & $101.08 \pm 17.56$ & $96.6 \pm 13.42$ & 0.786 & 0.439 & NS \\
\hline Height $(\mathrm{cm})$ & $157.8 \pm 7.56$ & $155.96 \pm 6.54$ & 0.71 & 0.484 & NS \\
\hline BMI (kg/m2) & $40.98 \pm 8.95$ & $39.83 \pm 5.92$ & 0.414 & 0.682 & NS \\
\hline : Probabi & & $\begin{array}{l}\text { S } \\
\text { NS }\end{array}$ & $\begin{array}{l}\text { Sign } \\
\text { Non }\end{array}$ & $\begin{array}{l}\text { ignifica } \\
\text { ignce. }\end{array}$ & \\
\hline
\end{tabular}

Table (2): The 2 X 2 mixed design Multivariate Analysis of Variance (MANOVA) for all dependent variables at different measuring periods between both groups.

\begin{tabular}{lll}
\hline Source of variation & F-value & $p$-value \\
\hline Groups & 1.081 & 0.353 \\
Measuring periods & 166.937 & $0.0001^{*}$ \\
Interaction & 1.978 & 0.158 \\
\hline
\end{tabular}

*: Significant at alpha level $<0.05$.

Table (3): Mean \pm SD and $p$-values of systolic blood pressure pre and post test at both groups.

\begin{tabular}{llllll}
\hline $\begin{array}{l}\text { Systolic blood } \\
\text { pressure }\end{array}$ & $\begin{array}{c}\text { Pre test } \\
\text { Mean } \pm \text { SD }\end{array}$ & $\begin{array}{c}\text { Post test } \\
\text { Mean } \pm \text { SD }\end{array}$ & MD & $\begin{array}{c}\% \text { of } \\
\text { change }\end{array}$ & $\begin{array}{c}p \text { - } \\
\text { value }\end{array}$ \\
\hline Group A & $149.73 \pm 7.75$ & $129.06 \pm 9.88$ & 20.66 & $13.79 \downarrow$ & $0.0001^{*}$ \\
Group B & $152.4 \pm 8.24$ & $134.86 \pm 8.5$ & 17.533 & $11.5 \downarrow$ & $0.0001^{*}$ \\
MD & -2.667 & -5.8 & & & \\
$p$-value & 0.369 & 0.096 & & \\
$*$ & : Significant level is set at alpha level <0.05. \\
SD : Standard Deviation. & & & \\
MD : Mean Difference. & & & \\
$p$-value : Probability value.
\end{tabular}

Table (4): Mean \pm SD and $p$-values of diastolic blood pressure pre and post test at both groups.

\begin{tabular}{llllll}
\hline $\begin{array}{l}\text { Diastolic blood } \\
\text { pressure }\end{array}$ & $\begin{array}{c}\text { Pre test } \\
\text { Mean } \pm \text { SD }\end{array}$ & $\begin{array}{c}\text { Post test } \\
\text { Mean } \pm \text { SD }\end{array}$ & MD & $\begin{array}{c}\% \text { of } \\
\text { change }\end{array}$ & $\begin{array}{c}p \text { - } \\
\text { value }\end{array}$ \\
\hline Group A & $94.2 \pm 4.10$ & $82.93 \pm 4.57$ & 11.267 & $11.96 \downarrow$ & $0.0001^{*}$ \\
Group B & $96 \pm 5.35$ & $83.33 \pm 6.48$ & 12.667 & $13.19 \downarrow$ & $0.0001^{*}$ \\
MD & -1.8 & -0.4 & & & \\
$p$-value & 0.311 & 0.847 & & & \\
\hline
\end{tabular}

\begin{tabular}{ll}
\hline$*$ & $:$ Significant level is set at alpha level $<0.05$. \\
SD & $:$ Standard Deviation. \\
MD & $:$ Mean Difference. \\
$p$-value : Probability value.
\end{tabular}

\section{Discussion}

This study was conducted to compare between the effects of interval aerobic exercise versus cupping therapy on stage: 1 essential hypertensive women. This study was conducted on Thirty women patients represented the sample of this study and all women suffered from stage I essential hypertension (140:160mmHg systole-90:100mmHg diastole) this study was conducted in outpatient internal medicine clinic in (Al-Safwa Clinic and Ain Shams Public Hospital in Ian Shams Region) from January 2014 to December 2016, they were diagnosed with specialized physician as stage one essential hypertension ,their age range from (3040). They were randomly divided into two groups equal in numbers.

Medical treatment and aerobic interval Group (A) included 15 female patient, how underwent medical treatment with interval aerobic training program 3 sessions per week for a month, medical treatment and cupping therapy Group (B) included 15 female patient, who underwent medical treatment and one cupping therapy session at the beginning of the study month.

Effect of aerobic interval exercise and cupping therapy on stage: 1 essential hypertensive women patients were examined through this study on the following variable: Blood pressure measurements by Sephengomanometer apparatus. This variable was measured initially before starting the program (pre) and after the end of program (post) in two groups. The results of current study there was significant reduction of systolic blood pressure at post treatment in compare to pre-treatment $(p-$ value $\left.=0.0001^{*}\right)$ and this mean there was improvement of systolic blood pressure in Group A and percent of change (improvement) was $13.79 \%$.

There was improvement of systolic blood pressure in Group B and percent of change (improvement) was $11.5 \%$, multiple pair wise comparison tests (post hoc tests) revealed that there was no significant difference of the mean values of the "post" test between both groups with $(p=0.096)$. In spite of there was no statistical significant difference between Group A and Group B, there was clinical difference and high percent of improvement in favor to Group A. There was improvement of diastolic blood pressure in Group A and percent of change (improvement) was $11.96 \%$. Multiple pair wise comparison tests (post hoc tests) revealed that there was significant reduction of diastolic blood pressure at post-treatment in compare to pre-treatment $(p$-value $=0.0001 *)$ and this mean there was improvement of diastolic blood pressure in Group B and percent of change (improvement) was $13.19 \%$. In spite of there was no statistical significant difference between Group A and Group B, there was clinical difference and high percent of improvement in favor to Group B. However, the interaction between the two independent variables was not significant, which indicates that the effect of the tested group (first independent variable) on the dependant variables was not influenced by the measuring periods (second independent variable). 
The results of this study came in accordance with Ingle et al., [5] who showed that the effectiveness of acupuncture therapy in glycosylated hemoglobin (HbA1C), lipid profile, Total Cholesterol (TC), serum triglyceride (TC), Low Density Lipoprotein (LDL), cholesterol, and BMI were significantly decreased from base line. The increased in the HDL-C were observed at the end of the study period. The results obtained were advantageous to the reversion of abnormal endocrine status and the metabolism of glucose and lipid at the same time achieving good therapeutic effect.

In agreement with the results of the current study Ahmad et al., [6] who found that HbA1C, triglyceride, cholesterol and lipoprptien with low density had a significant reduction and also a significant increase in lipoprotein rate with high density after treatment.

In agreement with the results of the current study Chirali [7] who said that cupping therapy is a physical treatment used by acupuncturists or other therapists that uses a plastic or glass cup to create suction to the skin over an acupuncture point or painful area.

In agreement with the results of the current study Shariat et al., [8] who said that cupping therapy may cause a reduction in various oxidative stress indexes.

In agreement with the results of current study Müzeyyen et al., [9]: Who said that cupping had therapeutic effects in rats with myocardial infarction and cardiac arrhythmias. The study investigates the possible useful effects of cupping therapy on cardiac rhythm in terms of Heart Rate Variability (HRV). Forty healthy participants were included. Classic wet cupping therapy was applied on five points of the back. Recording electrocardiography (to determine HRV) was applied 1 hour before and 1 hour after cupping therapy. All HRV parameters increased after cupping therapy compared with before cupping therapy in healthy persons. These results indicate for the first time in humans that cupping might be cardio protective. Cupping therapy restored sympathovagal imbalances by stimulating the peripheral nervous system. Wet Cupping Therapy Restores Sympathovagal Imbalances in Cardiac Rhythm.

The results of this study came in accordance with Ingle et al., [5] who reported that acupuncture points show significant effect on reduction of plasma glucose level, lipid profile and it also increases the level of high density lipoprotein at the same time.
The results of this study came in accordance with Aleyeidi et al., [10] who said that Wet-cupping therapy is effective for reducing systolic blood pressure in hypertensive patients for up to 4 weeks, without serious side effects. Wet-cupping should be considered as a complementary hypertension treatment, and further studies are needed.

In agreement with the results of the current studyNiasari et al., [11] who said that Wet cupping may be an effective method of reducing LDL cholesterol in men and consequently may have a preventive effect against atherosclerosis. A 7\% decrease in total cholesterol and 3\% increase in HDL cholesterol may be clinically important.

In agreement with the results of the current study, Izharul and Danish, [12] who said that alternative traditional regimes have proved to be highly successful in lowering high blood pressure and also promoting good health and wellness among patients. Hypertension or high blood pressure is typically caused when the blood thickens and becomes heavier over time. However in few people also have a larger volume of blood circulating in their bodies that causes blood pressure levels to rise. Cupping therapy and steam bath are noninvasive form of treatment, and works to eliminate the root causes of high blood pressure and draw out the thick and stagnant blood so that pure, light blood can circulate more freely.

In agreement with the results of current study Burgomaster et al., [13] the major novel finding from 6 weeks of SIT elicited adaptations in selected markers of skeletal muscle $\mathrm{CHO}$ and lipid metabolism and metabolic control during exercise that were comparable to those elicited by ET, despite a much lower training volume and time commitment. By design, weekly training volume was $\sim 90 \%$ lower in the SIT group ( $\sim 225$ versus $\sim 2250 \mathrm{~kJ}$ week ${ }^{-1}$ for ET) and necessitated a training timecommitment that was only one-third of that of the ET group ( 1.5 versus $4.5 \mathrm{~h})$. Most of the training time in the SIT group was spent in recovery between short, intense bursts of all out cycling and actual weekly exercise time was only $\sim 10 \mathrm{~min}$, as compared to $\sim 4.5 \mathrm{~h}$ of continuous moderate-intensity cycling in the ET group.

The present results confirm and extend the recent findings of Gibala et al., [14] of similar increases in muscle oxidative capacity and volitional exercise performance after six sessions of SIT or ET over 2 weeks.

The results of this study came in accordance with Gibala et al., [14] of prolonged sessions of 
moderate-intensity exercise (e.g. $\geq 1 \mathrm{~h}$ at $\sim 65 \%$ of peak oxygen uptake $\left(\mathrm{VO}_{2}\right.$ peak), performed repeatedly for at least several weeks, increases skeletal muscle oxidative capacity and alters substrate utilization during matched-work exercise, resulting in improved endurance capacity. Although lesswidely appreciated, numerous studies have shown that brief, repeated sessions of 'all out' highintensity or Sprint-type Interval Training (SIT) elicits changes in skeletal muscle energy metabolism that resemble traditional Endurance Training (ET).

In agreement with the results of current study who demonstrated that the interval-type exercise training methodology of Gibala et al., [1s , believed to induce more rapid physiological adaptations in skeletal muscle tissue than more continuous highintensity endurance-type exercise training. Most, but not all, data indeed seem to indicate that highintensity interval exercise training is more effective in increasing $\mathrm{VO}_{2}$ peak than continuous lowintensity exercise training in heart disease patients.

In agreement with the results of current study, Gibala et al., [14] demonstrated that 2.5 hours of sprint interval training produced similar biochemical muscle changes to 10.5 hours of endurance training and similar endurance performance enefits. According to a study by King, HIIT increases the Resting Metabolic Rate (RMR) for the following 24 hours due to excess post-exercise oxygen consumption, and may improve maximal oxygen consumption $\left(\mathrm{VO}_{2} \mathrm{max}\right)$ more effectively than doing only traditional, long aerobic workouts.

In agreement with the results of current studyCiolac, [16] demonstrated that High-intensity Interval Training (HIT), which consists of several bouts of high-intensity exercise ( $85 \%$ to $95 \%$ of $\mathrm{HR}_{\text {MAX }}$ and/or $\mathrm{VO}_{2 \mathrm{MAX}}$ lasting 1 to 4 min interspersed with intervals of rest or active recovery, is superior to CMT for improving cardiorespiratory fitness, endothelial function and its markers, insulin sensitivity, markers of sympathetic activity and arterial stiffness in hypertensive and normotensive at high familial risk for hypertension subjects. This compelling evidence suggesting larger beneficial effects of HIT for several factors involved in the pathophysiology of hypertension raises the hypothesis that HIT may be more effective for preventing and controlling hypertension.

The results of current study disagreed with Lee et al., [17] who included all Clinical Trials (CTs) of cupping to treat hypertension in human patients. Risk of bias was assessed using the Cochrane criteria. Two CTs met all inclusion criteria. One RCT (randomized CT) assessed the effectiveness of dry cupping on changes in cerebral vascular function compared with drug therapy. Their results suggested significant effect in favor of cupping on vascular compliance and degree of vascular filling. One Uncontrolled Observational Study (UOS) tested wet cupping for acute hypertension and found that a one-time treatment reduced blood pressure. In conclusion, the evidence is not significantly convincing to suggest cupping is effective for treating hypertension. Further research is required to investigate whether it generates any specific effects for that condition.

The results of current study disagreed with Jie and Xingjiang, [18] who said that after literature searching and analyzing, it appeared that CM was effective for hypertension in clinical use, such as Chinese herbal medicine, acupuncture, moxibustion, cupping, qigong, and Tai Chi. However, due to the poor quality of primary studies, clinical evidence is still weak. Evidence-based Chinese medicine for hypertension still has a long way to go.

\section{Conclusion:}

It was concluded that participation in aerobic interval exercise or cupping therapy have positive effect on blood pressure in stage one essential hypertensive women and can be used as alternative treatment modalities.

\section{References}

1- BREINL A.: Public Health and Tropical Medicine, James Cook University Journal, 10: 29-34, 2011.

2- CHOBANIAN A.V., BAKRIS G.L., BLACK H.R., et al.: Seventh report of the Joint National Committee on Prevention, Detection, Evaluation, and Treatment of High Blood Pressure, Hypertension J., 6: 42-52, 2003.

3- MACDONALD M.J. and CURRIEK D.: Interval exercise is a path to good health, but how much, how often and for whom? Clinical Science, 116: 315-3, 2009.

4- RASHID A.B.: Cupping as adjunctive therapy in the treatment of type 2 diabetes, hypertension and osteoarthritis, pilot research project; Bulane T.E., Kamdar Z., Staak W., Lambis M., Fakir A., Kisten N., Batchelor of Complementary Medicine (Unani-Tibb), Batchelor of Complementary Medicine, University of Western Cape, 7-9, 2008.

5- INGLE P.V., SAMDANI N.R., PATIAL P.H., PARDESHI M.S. and SURANA S.J.: Application of acupuncture therapy in type 2. International Journal of Pharmaceutical Sciences, Vol. 2, Issue 1, 2011.

6- AHMAD A., SEYED M.A., MAJID R., SEYED M.S., et al.: The Effect of Hijama (Cupping) on Oxidative Stress Indexes \& various Blood Factors in Patients Suffering 
from Diabetes Type II. Switzerland Research Park Journal, Vol. 102, No. 9, 2013.

7- CHIRALI I.Z.: Traditional Chinese medicine cupping therapy: Second edition, 2007.

8- SHARIAT ZADEH S.M.A., MALEKIRAD A.A. and SYADATI S.M.: Effect of cupping on oxidative stress. Journal of Medicine News, 4 (12): 53-4, 2005.

9- MÜZEYYEN A., NESIBE Y., DUYGU A., RAMAZAN Y., et al.: Wet Cupping Therapy Restores SympathovagalImbalances in Cardiac Rhythm. The Journal of Alternative and Complementary Medicine, 318-21, 2014.

10- ALEYEIDI N.A., ASERI K.S., MATBOULI S.M., et al.: Effects of wet-cupping on blood pressure in hypertensive patients: A randomized controlled trial. J. Integr. Med., 13 (6): 391-9. PMID, 2015.

11- NIASARI M., KOSARI F. and AHMADI A.: The effect of wet cupping on serum lipid concentrations of clinically healthy young men: A randomized control trial. J. Altern. Complement. Med., 13 (1): 79-82, 2007.

12- IZHARUL H. and DANISH K.: Hypertension and its management through Alternative Regimes of Unani Medicine. Research in Pharmacy and Health Sciences, Vol. 3 Issue 1: 280-4, 2017.
13- BURGOMASTER K.A., HOWARTH K.R., PHILLIPS S.M., et al.: Similar metabolic adaptations during exercise after low volume sprint interval and traditional endurance training in humans. J. Physiol., 1; 586 (1): 151-60, 2008.

14- GIBALA M.J., LITTLE J.P., VAN ESSEN M., WILKIN G.P., BURGOMASTER K.A., SAFDAR A., et al.: Shortterm sprint interval versus traditional endurance training: Similar initial adaptations in human skeletal muscle and exercise performance. J. Physiol., 575 (Pt 3): 901-11, 2006.

15- GIBALA M.J., LITTLE J.P., MacDONALD M.J. and HAWLEY J.A.: Physiological adaptations to low-volume, high-intensity interval training in health and disease. J. Physiol., 1; 590 (5): 1077-84, 2012.

16- CIOLAC G.E.: High-intensity interval training and hypertension: Maximizing the benefits of exercise? Am. J. Cardiovasc. Dis., 2 (2): 102-10, 2012.

17- LEE M.S., CHOI T.Y., SHIN B.C., et al.: Cupping for hypertension: Division of Standard Research, Korea Institute of Oriental Medicine, Daejeon, South Korea,National Center for Biotechnology Information. Asystematicreview: 32 (7): 423-5, 2010.

18 - JIE WANG and XINGJIANGX: Complementary and Alternative Medicine, Volume 1, 12 pages, 2013. 


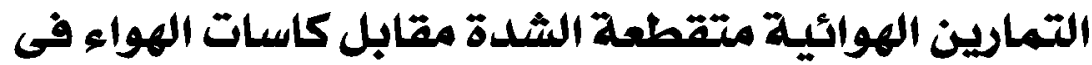

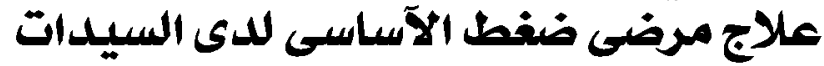

الفرض من الرسالة: تم إجراء هذا البحث لإظهار مدى إستجابة ضغط الدم المرضى ضغط الدم الآساسى الآولى المرتفع لبرنامج التمارين الرياضية الهوائية والعلاج بالحجامة.

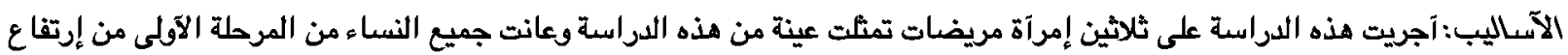

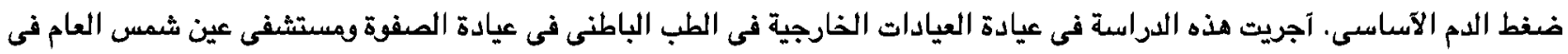

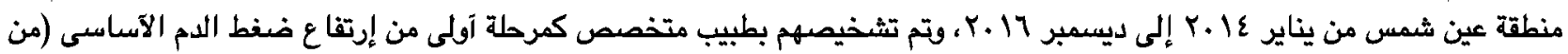

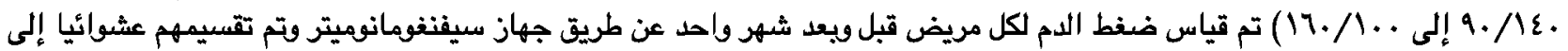

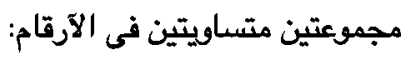

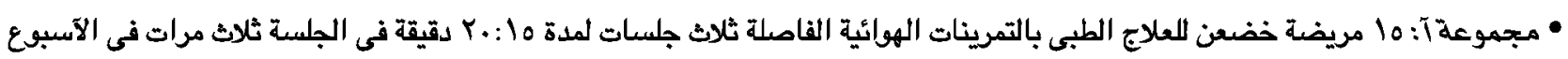
لمدة شهر.

• مجموعة ب: 10 مريضدة خضعن العلاج بالحجامة مرة واحدة شهريا لمدة عشرين دقيقة.

النتائج: نتائج الدراسة الحالية كانت هناك إنخفاض معنوى فى ضفط الدم الإنقباضى بعد العلاج مقارنة مع ما قبل المعالجة وهذا يعنى

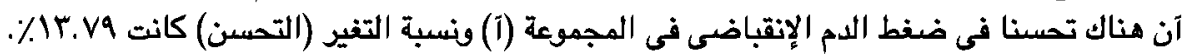

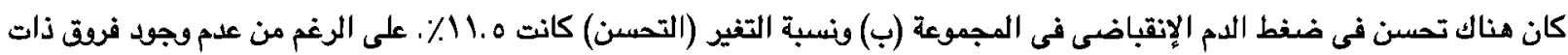

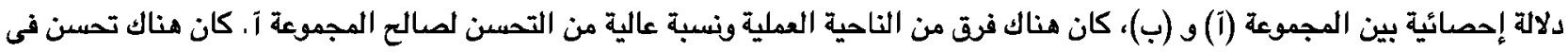

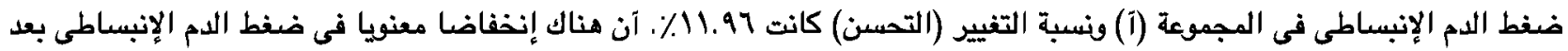

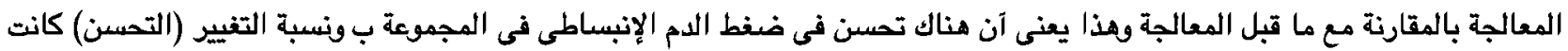
\% 1 . 19

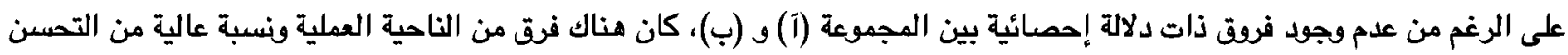

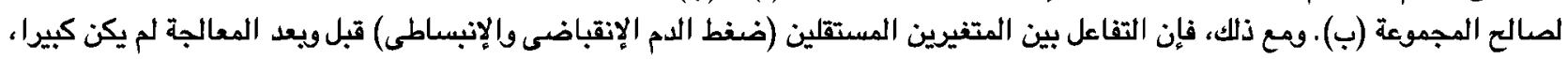

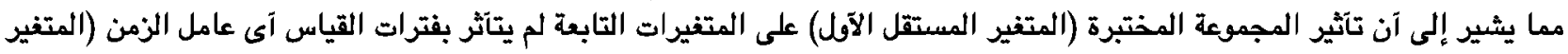

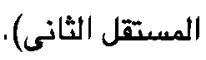

الإستتاج: العلاج بكاسات الهواء آو التمرينات الهوائية متقطعة الشدة له تآثير إيجابى ويمكن آستخدام آى منهما كوبسيلة علاجية بديلة

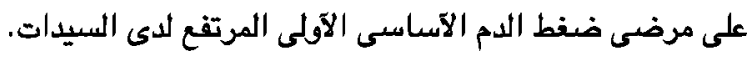

